\title{
An ultramicroscopic study of the skin in the diagnosis of the infantile and late infantile types of ceroid-lipofuscinosis ${ }^{1}$
}

\author{
M. L. ARSÉNIO-NUNES ${ }^{2}$ AND F. GOUTIÈRES 3 \\ From the Laboratoire de Neuropathologie and Service de Pédiatrie et Puériculture \\ Hôpital Saint Vincent de Paul, Paris, France
}

SYNOPSIS A skin biopsy was carried out in two children suffering from early infantile (Santavuori) and late infantile (Jansky-Bielschowsky) types of ceroid-lipofuscinosis. In both cases cytoplasmic inclusions, identical with those found in neurones, were present in the skin. Skin biopsy thus appears as a simple technique for the diagnosis of the ceroid-lipofuscinoses.

The storage material in various types of ceroidlipofuscinosis has been shown to be widely distributed outside the central nervous system (Kristensson et al., 1965). Examination of biopsy material from tissues more easily accessible than the central nervous system has therefore been used for diagnostic purposes in these disorders. Rectal or appendical biopsies have been most frequently performed for this purpose (Fawcett et al., 1966; Haelst and Gabreëls, 1972; Rapola and Haltia, 1973), but peripheral nerve biopsy has also been proposed (Joosten et al., 1973) as well as examination of blood lymphocytes (Witzleben et al., 1971).

Involvement of the skin in late infantile and juvenile types of ceroid-lipofuscinosis was first reported by Carpenter et al. (1972) and in a case of unidentified juvenile cerebromacular degeneration (Carpenter et al., 1973). Martin and Jacobs (1973) also stressed the potential interest of skin biopsy in late infantile amaurotic idiocy.

We wish to report the presence of cytoplasmic inclusions identical with those found in the neurons of the cerebral cortex and of the myenteric plexuses in a patient with late infantile ceroid-lipofuscinosis (Jansky-Bielschowsky type) and in a patient with early infantile lipofuscinosis

I This work was partially supported by the Institut National de la Santé et de la Recherche Médicale (INSERM) Paris, France.

2 Chargé de Recherche (INSERM).

3 Address for correspondence: F. Goutières, Hôpital Saint Vincent de Paul, Service du Professeur Thieffry, 74 avenue Denfert Rochereau, 75674 Paris CEDEX 14, France.

(Accepted 21 May 1975.)
(Santavuori et al., 1973). The results suggest that skin biopsy may be of interest in the diagnosis of these disorders.

\section{CASE 1}

A girl aged 4 years had normal psychomotor development until the age of 2 years 10 months. She then suffered generalized seizures and her mental condition deteriorated rapidly. At 4 years of age, continuous myoclonic jerks were noticed. Loss of vision was not apparent and optic fundi were normal but the electroretinogram was extinguished. The electroencephalogram revealed the appearance of large amplitude occipital spikes during photic stimulation, synchronous with each flash.

A cerebral biopsy, performed at the age of 4 years, showed swelling of many neurones due to storage of granular material, positive with Sudan black, Oil red $\mathrm{O}$ and PAS, and autofluorescent in ultraviolet light. The fine structure of this material consisted almost exclusively of small curvilinear profiles occurring in groups and surrounded by a continuous or interrupted unit membrane: they corresponded to the curvilinear bodies of Duffy et al. (1968) or cytosomes with curvilinear profiles of Carpenter et al. (1972). These inclusions were observed in the cytoplasm of the neurones, glia, endothelial cells, and pericytes.

A skin biopsy was performed at the age of 4 years 3 months.

CASE 2

A boy aged 3 years developed normally until the age of 13 months, when he began to show psychomotor 994 
regression and autistic behaviour; he did not have generalized seizures. At this age, the neurological examination was normal but he had incipient microcephaly (head circumference $<2$ SD). At the age of 3 years the child was blind, severely retarded, and began to exhibit myoclonic jerks; the optic discs were atrophic and the electroretinogram was extinguished. The electroencephalogram was of very low amplitude and there was no response to photic stimulation.

An appendicectomy was performed at the age of 3 years. The neurones of the myenteric plexus showed an accumulation of a granular material, positive with
Sudan black, Oil red $\mathrm{O}$ and PAS, and autofluorescent in ultraviolet light. This storage material was also present in macrophages and smooth muscle fibres. The ultrastructure of this material consisted of membrane-bound conglomerates of small globules which were finely granular.

A skin biopsy was performed at the age of 3 years 6 months.

\section{METHODS}

Skin samples, $5 \mathrm{~mm}$ long and $1 \mathrm{~mm}$ wide, were obtained under local anaesthesia induced by $2 \%$

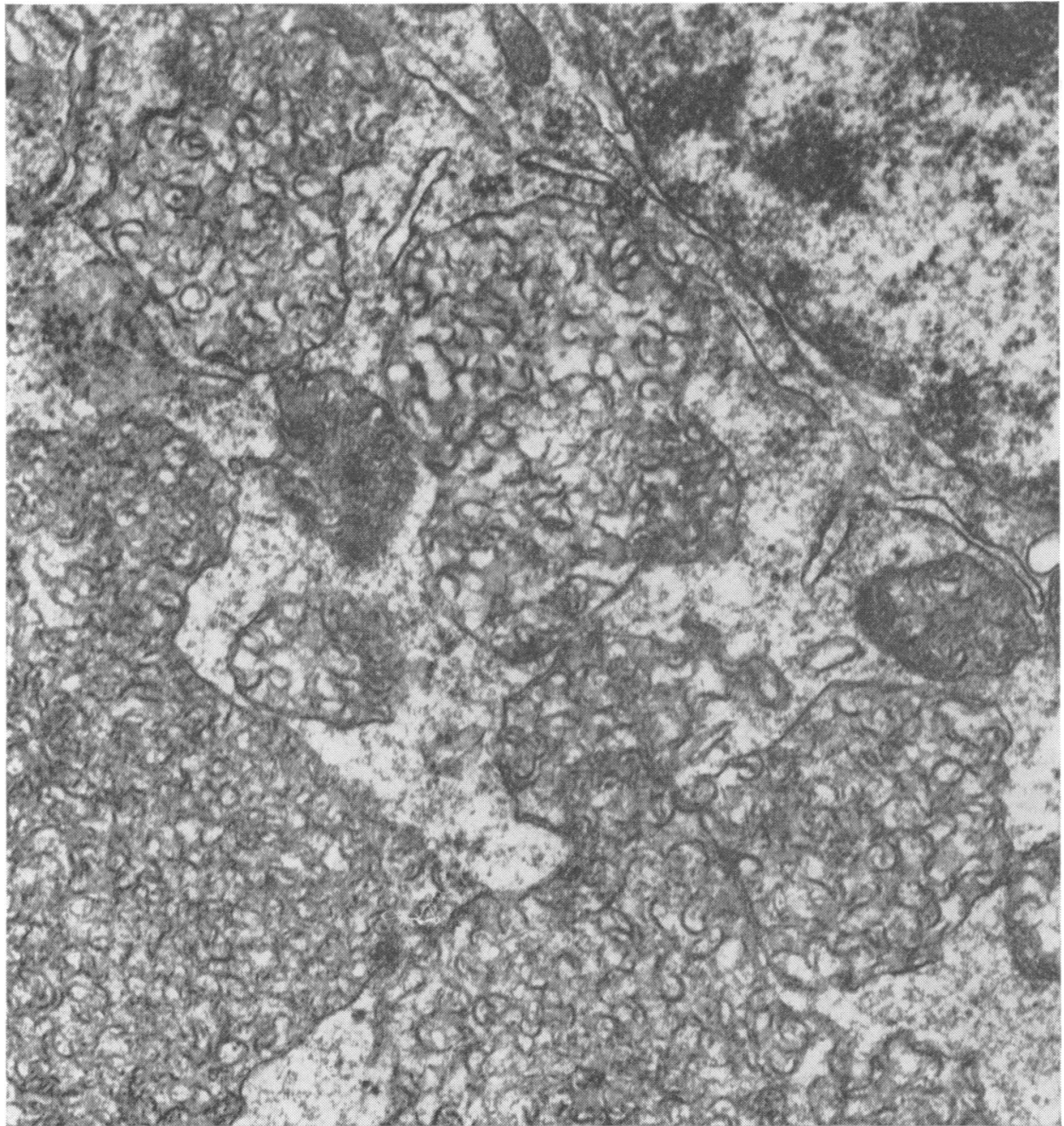

FIG. 1 Case 1. Multiple cytosomes with curvilinear profiles in the cytoplasm of a neurone of the cerebral cortex. Note the variability in size of the cytosomes, $\times 50000$. 
lignocaine, from the right scapular region in case 1 and from the lower quadrant of the abdomen in case 2. The fragments were immediately fixed in chilled $3.5 \%$ cacodylate-buffered mixture of glutaraldehyde and freshly prepared paraformaldehyde for two hours, rinsed in cacodylate buffer with sucrose, and post-fixed for two hours in $2 \%$ colidine-buffered osmium tetroxide. After in-block staining with uranyl acetate, the fragments were dehydrated and embedded in Araldite. Sections 1-2 $\mu \mathrm{m}$ thick were stained with toluidine-blue and observed under the light microscope to select the appropriate regions for ultrastructural study. Thin sections were stained by uranyl acetate and lead citrate and examined with a Siemens 101 electron microscope.

\section{RESULTS}

CASE 1 Electron microscopic examination showed large numbers of cytoplasmic inclusions in different types of skin cells. These inclusions consisted exclusively of cytosomes with curvilinear profiles, similar to those observed in the cortical cells (Fig. 1). These cytosomes varied in size and shape and were frequently arranged in clusters in the same section (Fig. 2). They were formed by multiple small curvilinear and parallel lamellae forming semicircles, crescents or, more rarely, full circles. The stacks of curvilinear profiles were surrounded by a unit membrane and usually almost completely filled the cytosome (Fig. 3).

The cytosomes were particularly numerous in the endothelial cells and the pericytes of the skin vessels but many were also seen in the epithelial cells and in eccrine sweat glands. More rarely, the cytosomes were seen in the Schwann cells of the nerves and in the fibroblasts.

CASE 2 The ultrastructural study of the skin biopsy specimen showed osmiophilic inclusions in the cytoplasm of several cells of various types.

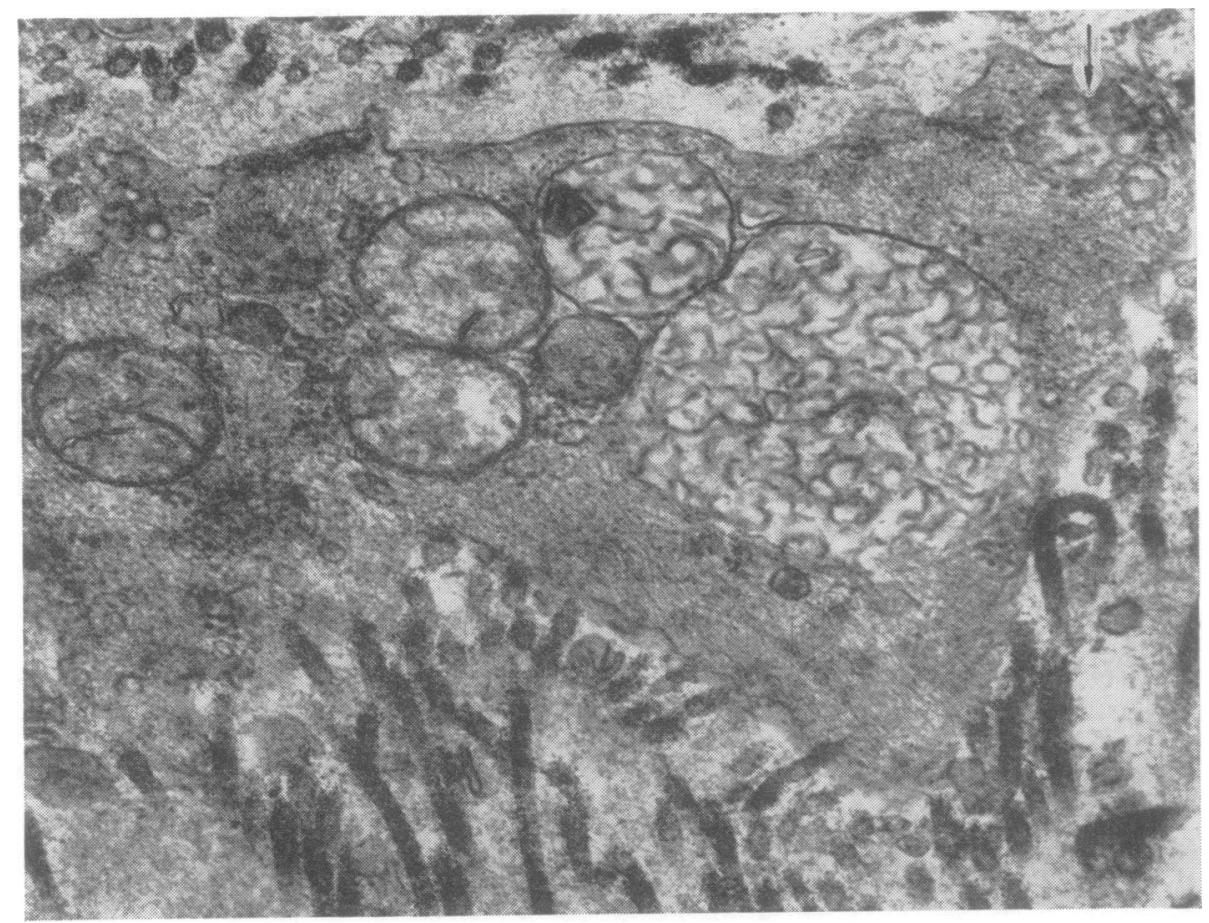

FIG. 2 Case 1. Two cytosomes with curvilinear profiles lie in a fibroblast of the skin. On the right there is a third cytosome (arrow) which is very small and ill-defined. The unit membrane surrounding the large cytosome is only partially apparent, $\times 50000$. 


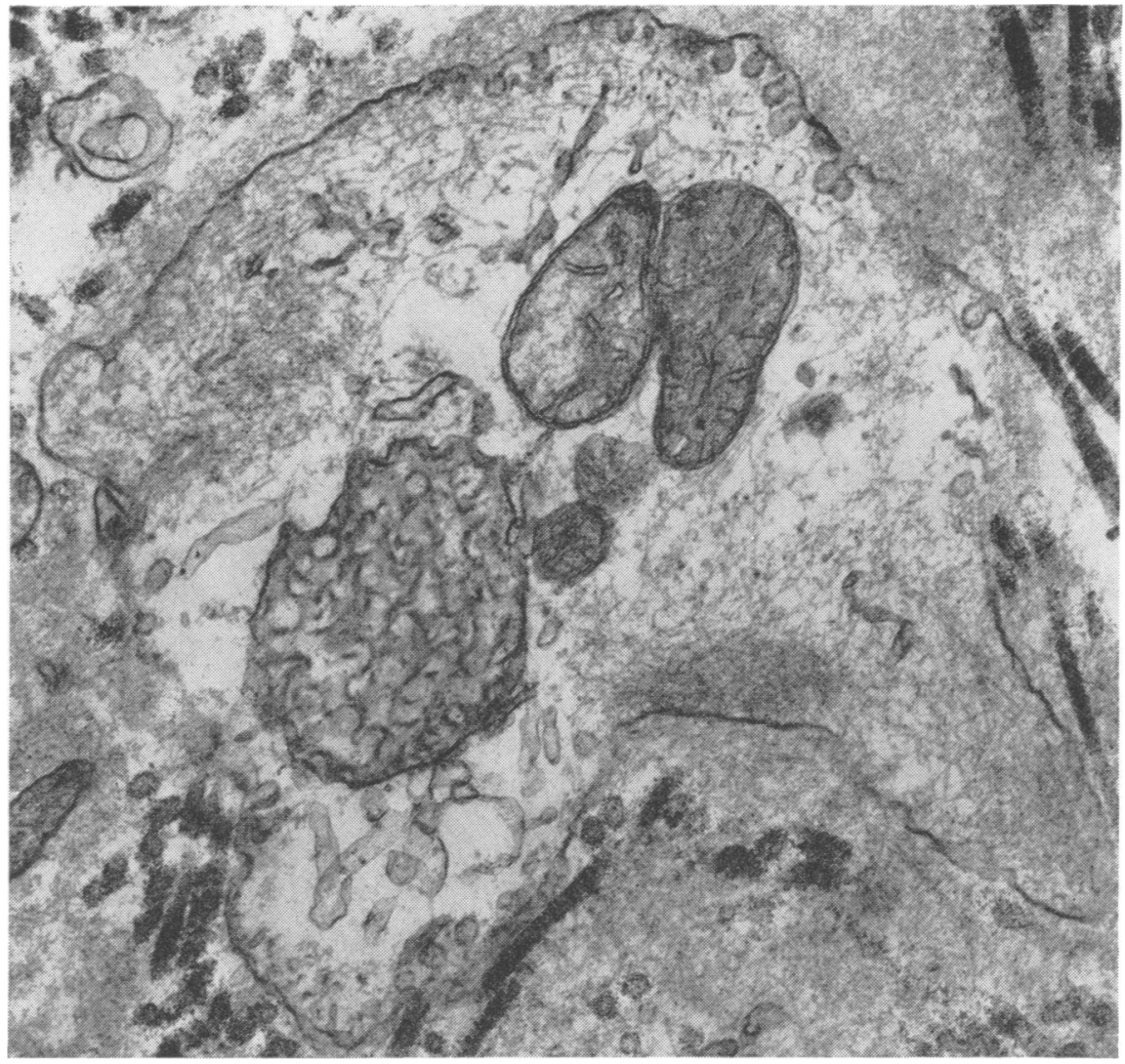

FIG. 3 Case 1. A single cytosome is present in a pericyte of a blood vessel situated in the dermis, $\times 50000$.

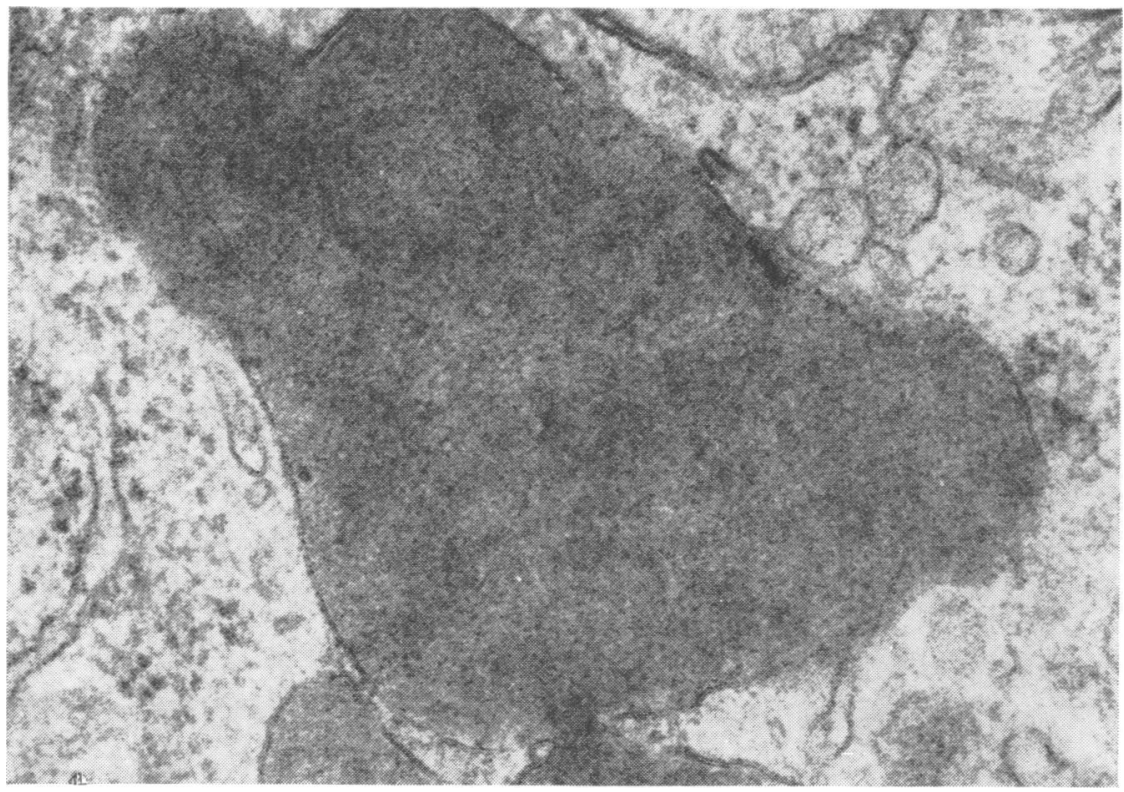

FIG. 4 Case 2.

Granular osmiophilic inclusion in the cytoplasm of a ganglion cell in the vermiform appendix, $\times 100000$. 
FIG. 5 Case 2. Two conglomerates of osmiophilic granular material are contained in the cytoplasm of an unidentified cell of the dermis, $\times 100000$.
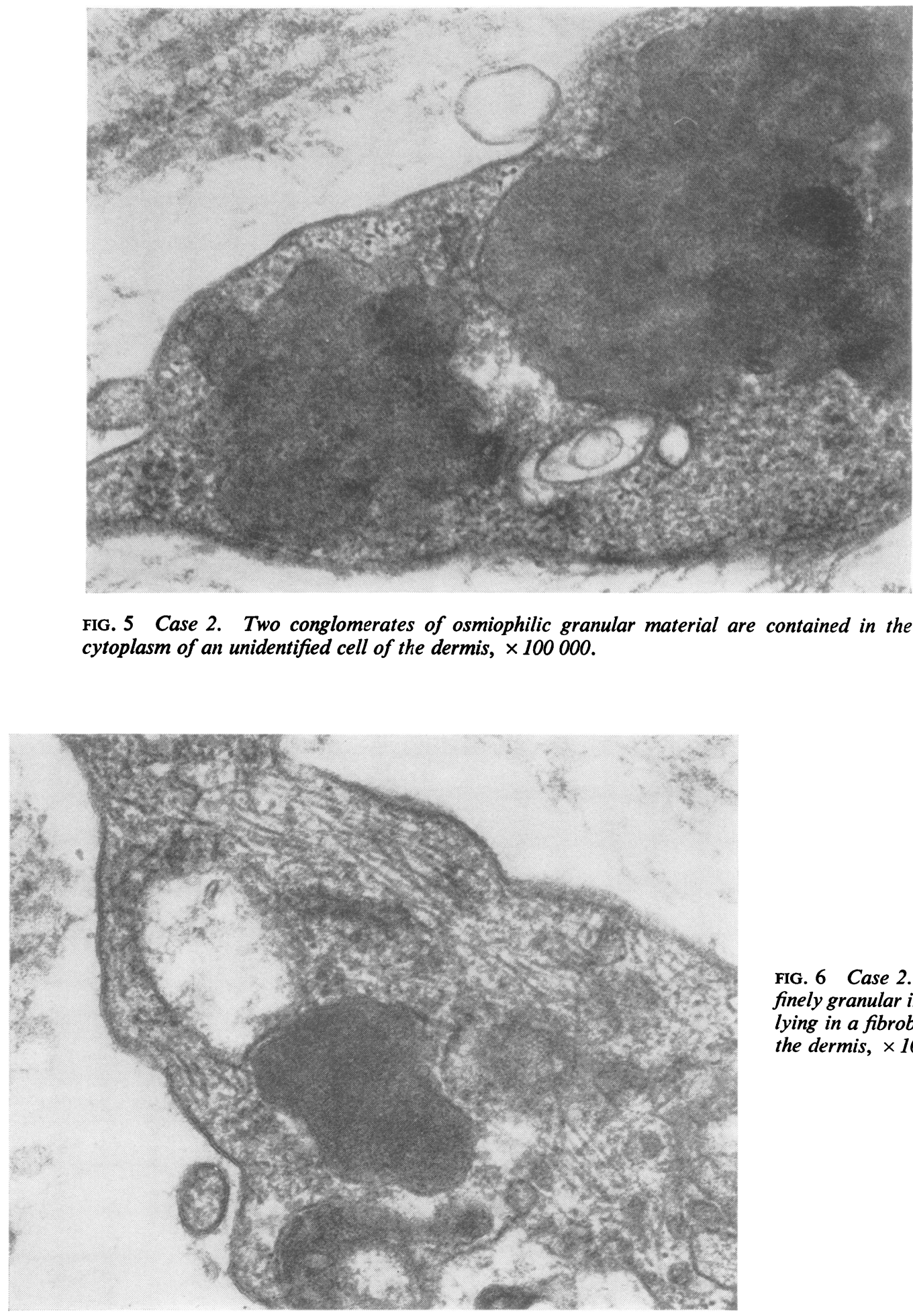

FIG. 6 Case 2. Small finely granular inclusion lying in a fibroblast of the dermis, $\times 100000$. 
These inclusions were identical with those found in the vermicular appendix (Fig. 4) and were also surrounded by a unit membrane which was not always apparent all along its contour. The size and shape of inclusions were variable but usually their largest diameter did not exceed $3 \mu \mathrm{m}$. Their fine structure was the same in all cells. It consisted of conglomerates of small globules which sometimes seemed to coalesce. These globules, more or less distinctly delimited (Fig. 5), had a fine granular structure (Fig. 6). Occasional membranous structures were observed among the granular material. The osmiophilic inclusions were present in the cytoplasm of fibroblasts, Schwann cells of peripheral nerves, vascular pericytes, and in some unidentified cells, probably modified fibroblasts.

\section{DISCUSSION}

Our results confirm previous reports of characteristic ultrastructural changes, similar to those found in the brain cortex, in skin cells from patients suffering from late infantile ceroidlipofuscinosis (Carpenter et al., 1972, Martin and Jacobs, 1973). In our case 1 , the curvilinear cytosomes were very numerous and easily demonstrated. This supports the contention of Martin and Jacobs that skin biopsy may be a suitable means of diagnosis in this disorder.

The results of the skin biopsy in our case 2 indicate that this technique may also be applicable in the early infantile form of ceroidlipofuscinosis. In this case, the granular inclusions were quite identical with those found in neurones of the appendicular plexuses. As shown by Rapola and Haltia (1973), the appendicular neurones in cases of early infantile ceroid-lipofuscinosis contain the same inclusions as the cortical cells (Haltia et al, 1973). The cytosomes, however, were relatively few and both the preparation and the examination of the biopsy specimen require particular attention.

The advantages of the skin biopsy are obvious since the procedure is non-invasive, easy to perform, and does not require general anaesthesia or hospitalization. Our data show that it is positive at a relatively early, as stagebiopsy was performed in our patients respectively 17 and 29 months after the clinical onset. More cases are needed to ensure that inclusions are found consistently in such cases.

Since cytoplasmic inclusions identical with those in the brain have also been demonstrated in skin cells of patients with Spielmeyer-Vogt disease (Carpenter et al., 1972), skin biopsy might prove to be a simple and convenient technique for the diagnosis of most forms of ceroid-lipofuscinosis.

\section{REFERENCES}

Carpenter, S., Karpati, G., and Andermann, F. (1972). Specific involvement of muscle, nerve and skin in late infantile and juvenile amaurotic idiocy. Neurology (Minneap.), 22, 170-186.

Carpenter, S., Karpati, G., Wolfe, L. S., and Andermann, F. (1973). A type of juvenile cerebromacular degeneration characterized by granular osmiophilic deposits. Journal of the Neurological Sciences, 18, 67-87.

Duffy, P. E., Kornfeld, M., and Suzuki, K. (1968). Neurovisceral storage disease with curvilinear bodies. Journal of Neuropathology, and Experimental Neurology, 27, 351-370.

Fawcett, J. S., Andermann, F., Wiglesworth, F. W., and Smith, D. L. (1966). On the natural history of late infantile cerebromacular degeneration. Neurology (Minneap.), 16, $1130-1134$.

Haltia, M., Rapola, J., and Santavuori, P. (1973). Infantile type of so-called neuronal ceroid-lipofuscinosis. Histological and electron microscopic studies. Acta Neuropathologica (Berl.), 26, 157-170.

Haelst, U. J. G. M. van, and Gabreëls, F. J. M. (1972). The electron microscopic study of the appendix as early diagnostic means in Batten-Spielmeyer-Vogt disease. Acta Neuropathologica (Berl.), 21, 169-175.

Joosten, E., Gabreëls, F., Stadhouders, A., Bolmers, D., and Gabreëls-Festen, A. (1973). Involvement of sural nerve in neuronal ceroid-lipofuscinosis. Neuropediatrie, 4, 98-110.

Kristensson, K., Rainer, S., and Sourander, P. (1965). Visceral involvement in juvenile amaurotic idiocy. Acta Neuropathologica (Berl.), 4, 421-424.

Martin, J. J., and Jacobs, K. (1973). Skin biopsy as a contribution to diagnosis in late infantile amaurotic idiocy with curvilinear bodies. European Neurology, 10, 281-291.

Rapola, J., and Haltia, M. (1973). Cytoplasmic inclusions in the vermiform appendix and skeletal muscle in two types of so called neuronal ceroid-lipofuscinosis. Brain, 96, 833840.

Santavuori, P., Haltia, M., Rapola, J., and Raitta, C. (1973). Infantile type of so-called neuronal ceroid-lipofuscinosis. A clinical study of 15 patients. Journal of the Neurological Sciences, 18, 257-267.

Witzleben, C. L., Smith, K., Nelson, J. S., Monteleone, P. L., and Livingston D. (1971). Ultrastructural studies in lateonset amaurotic idiocy: Lymphocyte inclusions as a diagnostic marker. Journal of Pediatrics, 79, 285-293. 